Case Study

\title{
Scoliosis in adulthood-a case with untreated early onset scoliosis presenting at the age of 76 years
}

HANS-RUdolf WeISS, MD ${ }^{1)}$

1) Orthopaedic Rehabilitation Services: Alzeyer Str. 23, D-55457 Gensingen, Germany

\begin{abstract}
Purpose] Untreated early-onset scoliosis may eventually progress to more than $90^{\circ}$ after growth, cause severe health problems, and increase chance of mortality. Therefore, surgical intervention is often indicated prior to the development of a life-threatening deformity. This case report aims to reveal how a 76-year-old male patient with curves exceeding $110^{\circ}$ is functioning with minimal difficulty. [Subject and Methods] The patient, who has never had surgical intervention for scoliosis, can perform his everyday activities. His curves were $111^{\circ}$ thoracic and $118^{\circ}$ lumbar when he presented at the author's office in January 2015. [Results] The patient reported that he rarely needs a physician and participates in endurance sports like jogging. Despite this, the patient recognizes his restrictive ventilation disorder (shortness of breath) when he is inactive. The patient complained of shortness of breath and cosmetic concerns. [Conclusion] The current guidelines indicate that early-onset scoliosis should be operated at a young age; however, this protocol is not supported by high-quality evidence. Notably, patients with curvatures exceeding $100^{\circ}$ after puberty may have a reasonable quality of life when they lead an active life with regular participation in endurance sports and physical rehabilitation.

Key words: Early onset scoliosis, Endurance sports, Physical rehabilitation
\end{abstract}

(This article was submitted Jul. 4, 2016, and was accepted Aug. 23, 2016)

\section{INTRODUCTION}

Patients with untreated adolescent idiopathic scoliosis (AIS) rarely progress to a degree of curvature which may cause a significant impairment in general health ${ }^{1}$. Aging patients with AIS generally function well in a 50 year follow-up of untreated scoliosis ${ }^{2}$. However, early-onset scoliosis (EOS), which typically exceeds $90^{\circ}$ after growth when left untreated ${ }^{3)}$, can lead to severe health problems (mainly cor pulmonale) and an increased chance of mortality ${ }^{4,5)}$. Therefore, surgical intervention is often indicated for these cases before a life-threatening deformity develops ${ }^{6}$.

A case series ${ }^{6}$ and several long-term case reports ${ }^{7-11)}$ have demonstrated that while patients who have had spinal fusion surgery may function well later on, they regularly need re-operations. Few publications have shown untreated cases in aging patients and curvatures exceeding $100^{\circ 1,4,5}$. The present case report aims to demonstrate how an untreated 76 -year-old male patient with $118^{\circ}$ lumbar $/ 111^{\circ}$ thoracic scoliosis is functioning.

\section{SUBJECT AND METHODS}

A 76-year-old man with severe curvatures of $111^{\circ}$ thoracic and $118^{\circ}$ lumbar presented at the office of the author in January 2015 (Fig. 1). His scoliosis was first observed before he was 4 years old. The patient reported having no brace treatment or surgery over the course of his lifetime and rarely needing a physician. He participated in regular sports activities and was treated by a physiotherapist in Germany for his scoliosis. His office visit marked the fourth time in his life he has had radio- 
graphs. He stays active by participating in endurance sports like jogging but recognizes his restrictive ventilation disorder (shortness of breath) when he is inactive. The patient never considered scoliosis surgery. His only complaints are shortness of breath and cosmetic concerns.

\section{RESULTS}

The sole reason for the patient's visit was to inquire whether his exercises and sports are appropriate for his condition. The author examined the patient clinically and suggested a radiograph to determine the appropriate advice. The patient initially did not want to undergo radiography, but consented after the author explained its necessity in the absence of any of the patient's previous radiographs. The radiograph revealed a wellbalanced double major curve pattern. The angle of trunk rotation at presentation exceeded $30^{\circ}$ on both curves. The patient's forced vital capacity (VC) is 1.4 liters - less than $50 \%$ of the predicted value, when measured according to his current height. When estimating the patient's expected height without scoliosis, his VC is less than $30 \%$ of the predicted value. The diagnosis on the record (Fig. 2) was "severe restrictive ventilation disorder." Dyspnea is evident while talking as he draws breath sharply in between his sentences.

\section{DISCUSSION}

Winter and Lonstein ${ }^{6)}$ reported a case of long-term follow-up after early surgery for pediatric spinal deformity. Their case series includes patients with scoliosis of different etiologies. Their non-operative cases show a poor outcome. One patient, with a decompensated single thoracic curve, suffered a collapsing spine and early death due to severe cor pulmonale.

Several case reports ${ }^{7-11}$ conclude that early surgery is necessary to achieve the best possible results. However, nearly all of the patients required reoperation and some experienced disabling chronic pain. Alternatively, the patient discussed in this case report demonstrates that not all patients with EOS would choose scoliosis surgery retrospectively, even more than 70 years after the initial diagnosis.

Given the contrasting cases presented, stating that scoliosis surgery is lifesaving is definitively impossible ${ }^{7)}$. Some patients with curvatures exceeding $100^{\circ}$ after growth, such as this man, are living a reasonable life without surgery, although not without distinct challenges.

The current state of scoliosis literature largely ignores this patient population for various reasons. A lack of follow-up may occur between patients and their physicians, particularly those who resist surgical intervention. Patients who were recommended for surgery may also seek alternative treatments or no treatment at all. However, to date, parents of children diagnosed with EOS are less likely to refuse scoliosis treatment. The reason for this is that evidence now exists showing that scoliosis may potentially progress without intervention, especially in high-risk cases such as EOS ${ }^{1)}$. Furthermore, bracing can successfully halt or slow curve progression for patients and families not willing to consent to surgery ${ }^{12}$. Newly developed 3D braces supported by specific exercises have been shown to be highly corrective and can be used to successfully treat early-onset pediatric spinal deformities ${ }^{12,13}$. This computer-aided bracing technology, designed according to curve classification $^{14)}$, offers the possibility of improving EOS during the pubertal growth spurt, not just stopping curvature progression (Fig. 3).

At present, no evidence suggests that scoliosis surgery is superior to the natural history of the condition ${ }^{15-19)}$. Moreover, the long-term effects of spinal fusion may lead to a high reoperation rate ${ }^{15,20,21)}$ and other long-term complications ${ }^{21,22)}$. When treating EOS and congenital scoliosis ${ }^{23}$, high-quality conservative treatment ${ }^{24)}$ should be attempted to avoid spinal surgery. In light of new developments in the field of scoliosis research, only a small subset of patients with early-onset spinal deformities treated with bracing ${ }^{14)}$ may require scoliosis surgery.

Finally, the patient from this case report never consulted a spine surgeon during the course of his adult life. This implies that a subset of EOS patients who have declined surgery exists. As a result, these patients are not included in studies put forth by spine surgeons. In addition, we have to consider that patients suffering from adverse effects of spine surgery are often lost to follow-up ${ }^{25}$. This may cause a reasonable bias in publications on this topic.

A case report is of limited evidence. However, a phenomenon exists wherein untreated scoliosis patients with curvatures exceeding $100^{\circ}$ may have a reasonable quality of life and would not choose to undergo surgery. More cases of untreated patients and curvatures exceeding $100^{\circ}$ need to be found and published to gain more evidence.

In conclusion, the surgery practice for EOS is not supported by a high-quality research. Patients with curvatures exceeding $100^{\circ}$ after puberty may have a reasonable quality of life when they lead an active life with regular participation in endurance sports and physical rehabilitation. In the absence of symptoms, some patients do not want surgery. Severe cases, as reported in literature, now have the potential to be managed with high-quality conservative treatment rather than immediate surgery.

\section{Conflict of interest}

HR Weiss is receiving financial support for attending symposia and receives royalties from Koob GmbH \& Co KG. The company is held by the spouse of HR Weiss. 

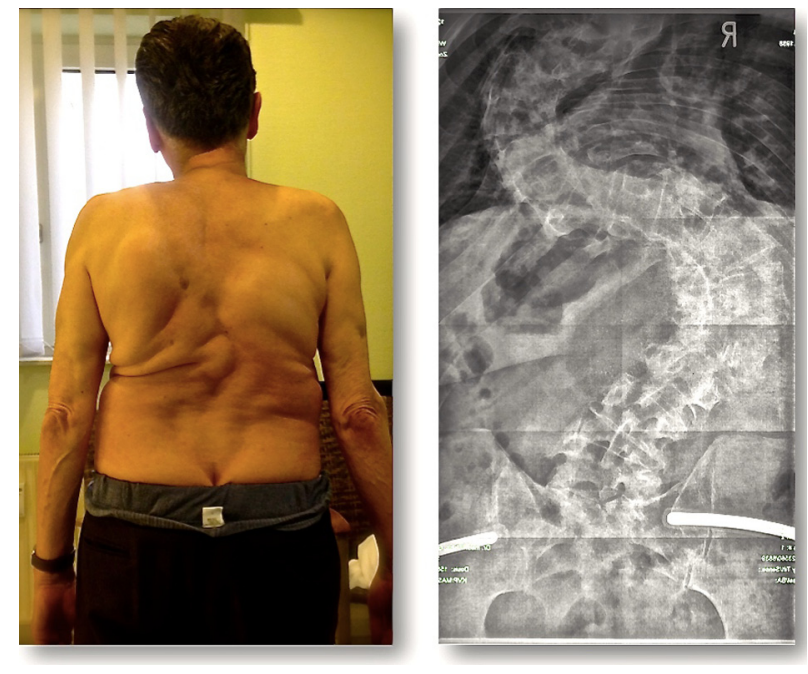

Fig. 1. Left: Clinical picture of the patient described in this case report, from the back. Right: X-ray taken at the time of the latest presentation in January 2015. The Cobb angles of the patient were $111^{\circ}$ thoracic and $118^{\circ}$ lumbar.
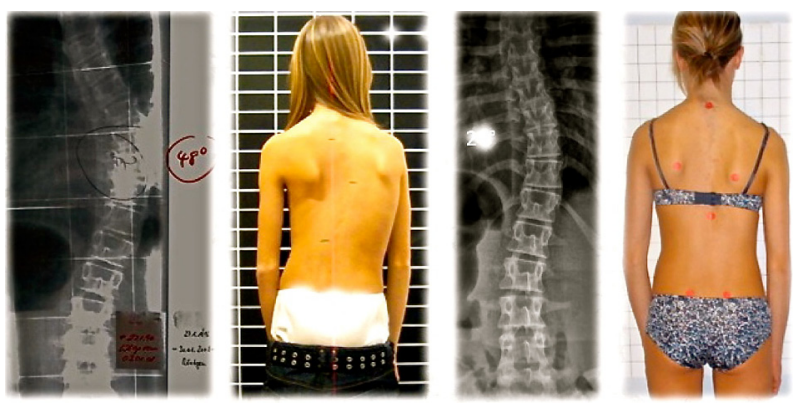

Fig. 3. Left: Early onset scoliosis patient with a curvature of $48^{\circ}$ at the start of the pubertal growth spurt. She has been treated with a computer-aided design Chêneau-style Gensingen brace. Right: After brace weaning, she appears more balanced with a residual curvature of $24^{\circ}$.

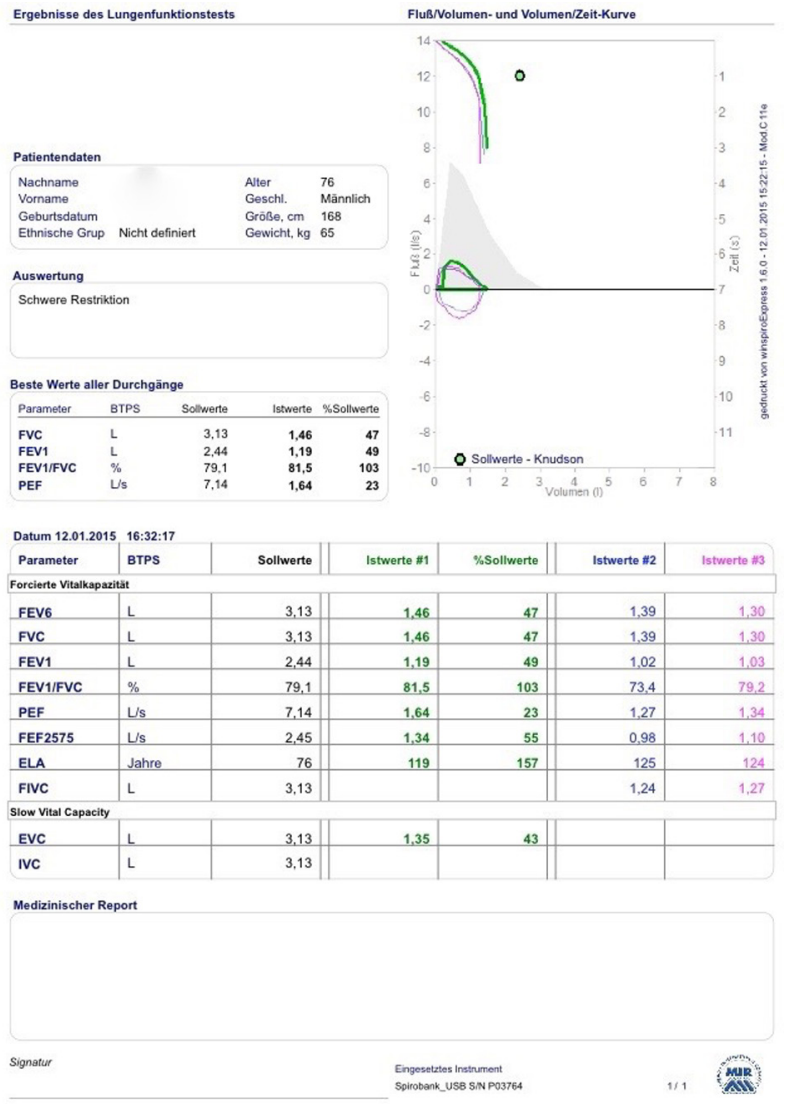

Fig. 2. Patient's pulmonary function report (January 12, 2015). The report is in German and is used for docuentation purposes only. His forced vital capacity measured 1.4 liters, which is $47 \%$ of the predicted value. When measuring predicted value according to the patient's expected height without scoliosis, his forced vital capacity is less than $30 \%$ of the predicted value. The recorded diagnosis was "severe restrictive ventilation disorder."

\section{ACKNOWLEDGEMENTS}

HRW drafted and conducted the research. The first draft was copyedited in English by Kathryn Moramarco. The author would like to thank Editage (www.editage.com) for English language editing of the final version. A written informed consent was obtained from the patient to publish his data, clinical pictures, and radiographs within scientific articles. This paper is dedicated to Christa Lehnert-Schroth (+ March 22, 2015), an eminent pioneer in conservative scoliosis management and the author's mother.

\section{REFERENCES}

1) Asher MA, Burton DC: Adolescent idiopathic scoliosis: natural history and long term treatment effects. Scoliosis, 2006, 1: 2. [Medline] [CrossRef]

2) Weinstein SL, Dolan LA, Spratt KF, et al.: Health and function of patients with untreated idiopathic scoliosis: a 50-year natural history study. JAMA, 2003, 289: 559-567. [Medline] [CrossRef]

3) Goldberg CJ, Moore DP, Fogarty EE, et al.: The natural history of early onset scoliosis. Stud Health Technol Inform, 2002, 91: 68-70. [Medline]

4) Pehrsson K, Larsson S, Oden A, et al.: Long-term follow-up of patients with untreated scoliosis. A study of mortality, causes of death, and symptoms. Spine, 
1992, 17: 1091-1096. [Medline] [CrossRef]

5) Pehrsson K, Danielsson A, Nachemson A: Pulmonary function in adolescent idiopathic scoliosis: a 25 year follow up after surgery or start of brace treatment. Thorax, 2001, 56: 388-393. [Medline] [CrossRef]

6) Winter RB, Lonstein JE: Ultra-long-term follow-up of pediatric spinal deformity problems: 23 patients with a mean follow-up of 51 years. J Orthop Sci, 2009, 14: 132-137. [Medline] [CrossRef]

7) Winter RB, Lonstein JE: Congenital scoliosis with posterior spinal arthrodesis T2-L3 at age 3 years with 41-year follow-up. A case report. Spine, 1999, 24: 194-197. [Medline] [CrossRef]

8) Winter RB, Lonstein JE: Adolescent idiopathic scoliosis: case report with 63-year follow-up postsurgery. Spine, 2003, 28: E441-E444. [Medline] [CrossRef]

9) Winter RB, Smith MD, Lonstein JE: Congenital scoliosis due to unilateral unsegmented bar: posterior spine fusion at age 12 months with 44 -year follow-up. Spine, 2004, 29: E52-E55. [Medline] [CrossRef]

10) Winter RB, Lonstein JE: Congenital thoracic scoliosis with unilateral unsegmented bar and concave fused ribs: rib osteotomy and posterior fusion at 1 year old, anterior and posterior fusion at 5 years old with a 36-year follow-up. Spine, 2007, 32: E841-E844. [Medline] [CrossRef]

11) Winter RB: Congenital thoracic scoliosis with unilateral unsegmented bar, convex hemivertebrae, and fused concave ribs with severe progression after posterior fusion at age 2: 40-year follow-up after revision anterior and posterior surgery at age 8. Spine, 2012, 37: E507-E510. [Medline] [CrossRef]

12) Weiss HR: Brace treatment in infantile/juvenile patients with progressive scoliosis is worthwhile. Stud Health Technol Inform, 2012, 176: 383-386. [Medline]

13) Weiss HR: Successful brace treatment in infantile/juvenile patients is possible- an example of a patient with progressive scoliosis due to Marfans' syndrome. Fachmesse Orthopädie + Reha-Technik 2012 + ISPO World Conference, 2012.

14) Weiss HR, Kleban A: Development of CAD/CAM based brace models for the treatment of patients with scoliosis - classification based approach versus finite element modelling. Asian Spine J, 2015, 9: 661-667. [Medline] [CrossRef]

15) Hawes M: Impact of spine surgery on signs and symptoms of spinal deformity. Pediatr Rehabil, 2006, 9: 318-339. [Medline] [CrossRef]

16) Hawes MC, O’Brien JP: A century of spine surgery: what can patients expect? Disabil Rehabil, 2008, 30: 808-817. [Medline] [CrossRef]

17) Westrick ER, Ward WT: Adolescent idiopathic scoliosis: 5-year to 20-year evidence-based surgical results. J Pediatr Orthop, 2011, 31: S61-S68. [Medline] [CrossRef]

18) Bettany-Saltikov J, Weiss HR, Chockalingam N, et al.: Surgical versus non-surgical interventions in people with adolescent idiopathic scoliosis. Cochrane Database Syst Rev, 2015, 4: CD010663. [Medline]

19) Ward WT, Roach JW, Friel N, et al.: SRS 22r scores in non-operated AIS patients with curves $\geq 40^{\circ}$. Proceedings of the 50th Annual Meeting Minneapolis, Minnesota, USA, 2015, September 30th-October 3rd.

20) Mueller FJ, Gluch H: Cotrel-dubousset instrumentation for the correction of adolescent idiopathic scoliosis. Long-term results with an unexpected high revision rate. Scoliosis, 2012, 7: 13. [Medline] [CrossRef]

21) Weiss HR, Goodall D: Rate of complications in scoliosis surgery—a systematic review of the Pub Med literature. Scoliosis, 2008, 3: 9. [Medline] [CrossRef]

22) Weiss HR, Moramarco M: Indication for surgical treatment in patients with adolescent idiopathic scoliosis-a critical appraisal. Patient Saf Surg, 2013 , 7: 17. [Medline] [CrossRef]

23) Weiss HR, Moramarco M: Congenital scoliosis (Mini-review). Curr Pediatr Rev, 2016, 12: 43-47. [Medline] [CrossRef]

24) Weiss H, Lehnert-Schroth C, Moramarco M, et al.: Schroth therapy-advancements in conservative scoliosis treatment. Saarbrücken: Lambert Academic Publishing, 2015.

25) Trobisch PD, Ricart P, Bharucha N: [Clinical characteristics of patients who are lost to follow-up after surgical treatment for adolescent idiopathic scoliosis]. Z Orthop Unfall, 2012, 150: 48-51. [Medline] 